\title{
Estudos internacionais sobre inovação no setor público: como a teoria da inovação em serviços pode contribuir?
}

\author{
Dagomar Henriques Lima \\ Tribunal de Contas da União \\ Eduardo Raupp de Vargas \\ Universidade de Brasília
}

\begin{abstract}
O artigo tem por objetivo situar a discussão atual sobre inovação no setor público em revistas internacionais, em confronto com a teoria da inovação em serviços, visando identificar oportunidades de pesquisa. Os artigos revisados foram recuperados da base science direct referente ao período de 2006 a 2010. O exame dos artigos foi realizado com base em seis categorias de análise que serviram para revelar as abordagens adotadas pelos autores. Conclui-se que os autores dos estudos da amostra têm interação restrita com a literatura de inovação em serviços. Os artigos revelam visão da inovação como mudança imposta de cima para baixo e não como processo interativo e intrínseco à atividade pública. São identificadas oportunidades de pesquisa mais detalhadas no nível organizacional e no nível micro, que reconheçam as especificidades do setor público.
\end{abstract}

Palavras-chave: teoria da inovação em serviços; setor público; abordagem integradora.

International studies on innovation in the public sector: how the theory of innovation in services can contribute?

The article puts in perspective the current discussion about public sector innovation in international journals, in comparison with the theory of innovation in services, aiming to identify research opportunities. Articles reviewed were retrieved from the science direct basis for the period 2006 to 2010 . The articles review was based on six categories of analysis that served to reveal the authors approaches. We conclude that the authors of the sampled studies have limited interaction with the literature of innovation in services. Innovation is approached as a change imposed from the top down in contrast with an approach of innovation as an interactive process intrinsic to public administration. It identifies opportunities for more detailed research at the organizational level and at the micro level which recognize the specificities of the public sector.

KEY WORDS: service innovation theory; public sector; integrative approach.

Artigo recebido em nov. 2010 e aceito em jul. 2011.

RAP - Rio de Janeiro 46(2):385-401, mar./abr. 2012 


\section{Introdução}

Este artigo objetiva situar a discussão sobre inovação no setor público, visando identificar oportunidades de pesquisa. Para isso, procurou-se estabelecer diálogo entre autores de estudos internacionais sobre inovação no setor público e autores da literatura de inovação em serviços que adotam a abordagem integradora (Gallouj e Savona, 2009). Trata-se, portanto, de pesquisa bibliográfica em artigos em língua inglesa, que foram analisados sob o enfoque da teoria de inovação em serviços.

A inovação em serviços é um ramo dos estudos de inovação cuja literatura vem se desenvolvendo de forma significativa, trazendo contribuições teóricas e empíricas que ajudam a compreender melhor os processos de inovação na economia e a própria dinâmica do desenvolvimento econômico. No entanto, ainda há amplo campo para pesquisa sobre inovação no serviço público, principalmente sobre seus resultados, em razão da pouca atenção que vem sendo dispensada a esse ramo da atividade econômica e social (Koch e Hauknes, 2005).

Os estudos sobre inovação são parciais ao se voltar quase exclusivamente para a análise desse fenômeno em firmas com regulação de mercado. Nesses estudos, o setor público é tratado como criador de arcabouço legal regulatório, como financiador de atividades de inovação, como consumidor de produtos inovadores gerados pelo setor privado ou produtor de bens complementares (como infraestrutura), poucas vezes, no entanto, como protagonista de processos de inovação (Koch e Hauknes, 2005; Windrum; García-Goñi, 2008).

A parcialidade dos estudos sobre inovação é tanto mais grave na medida em que a relevância social e econômica dos setores público e de serviços (públicos e privados) na economia torna a investigação de seus processos de inovação mais importante para a compreensão desse fenômeno na sociedade. Por exemplo, no Brasil, em 2008, 21\% das ocupações formais eram relacionadas ao serviço público (Ipea, 2009) e a despesa primária ${ }^{1}$ foi de $33,4 \%$ do PIB em 1999 (IBGE, 2006).

Por sua vez, o marco teórico usado para analisar o setor comercial vem sendo aplicado nos estudos sobre inovação nos serviços públicos. Visando reconhecer as especificidades do setor público, e no contexto de um esforço de pesquisa financiado pela União Europeia, Koch e Hauknes (2005:9) apresentam uma definição de inovação no setor público que reconhece o caráter contextual da natureza do resultado da inovação: "Inovação é a implementação ou desempenho de uma nova forma específica ou repertório de ação social, implementada deliberadamente por uma entidade no contexto dos objetivos e funcionalidades de suas atividades". Essa é a definição que usaremos neste artigo por permitir melhor operacionalizar a análise do processo de inovação no setor público.

\footnotetext{
${ }^{1}$ Essa medida inclui o consumo público (gastos com pessoal e custeio), os subsídios e transferências ao setor privado (excluídos os pagamentos de juros e despesas financeiras) e o investimento público.
} 
A principal limitação deste artigo é a restrição da pesquisa à base science direct no período de cinco anos. Versão mais abrangente poderia usar ferramentas de busca integrada, que incluam outras bases de dados, e estender o período de pesquisa.

Além desta introdução e da seção conclusiva, este artigo compõe-se de mais quatro partes. A primeira resume formulações teóricas sobre inovação em serviços e no setor público. A segunda descreve o método adotado nesta revisão, seguida da terceira parte, que sintetiza as pesquisas revisadas, destacando seus objetivos e resultados. A quarta parte discute criticamente os artigos revisados, segundo categorias de análise definidas pelo método, e os confronta com a teoria de inovação em serviços.

\section{Marco teórico}

Desde os trabalhos de Schumpeter (1982) no início do século XX e depois, na década de 1980, com o livro fundamental de Nelson e Winter (2005), publicado em 1982, a inovação tem sido reconhecida como uma das características essenciais das economias contemporâneas e motor do desenvolvimento econômico. No entanto, dificilmente é associada ao setor serviços, pois prevalece uma visão tecnicista da inovação, associando-a predominantemente à manufatura.

A teoria de inovação em serviços nasce como uma tentativa de entender o processo de inovação no setor que, desde a década de 1960 (Gadrey, 2001), ganha relevância crescente nas economias modernas e hoje representa a maior parte do produto dessas economias.

Os primeiros estudos sobre inovação em serviços eram fortemente influenciados por pesquisas de inovação no setor industrial. Eles integram a abordagem tecnicista sobre inovação em serviços (Gallouj, 2002). Para a abordagem tecnicista, a inovação em serviços equivale à inovação tecnológica, no sentido tradicional desta palavra, proveniente da indústria.

A abordagem tecnicista abrange estudos de inovação afetados por crenças sobre o setor serviços, que o carrega com imagem de ser improdutivo, de baixa produtividade, de baixa intensidade na aplicação de capital e de empregar pessoal com baixa qualificação. Além disso, os serviços têm especificidades relacionadas à sua natureza interativa, intangível, processual e diversificada, o que torna inapropriado estudá-los segundo o mesmo arcabouço teórico usado para estudar o setor industrial (Gallouj, 2002).

Como reação à abordagem tecnicista, posteriormente surgiram estudos classificados como filiados à abordagem baseada em serviços. Para Gallouj (2002:19), essa abordagem adota um ou dois dos seguintes objetivos: 1) destacar a existência de formas particulares de inovação em serviços, consequência de sua natureza intangível e interativa, 2) produzir teorias locais, aplicáveis a atividades específicas de serviços, consequência de sua diversidade. Para Vargas (2006:74), a ideia central desse enfoque é que, mais importantes que as inovações tecnológicas, são as inovações produzidas na interação entre cliente e prestador, definida por Gadrey (2001) como relação de serviço. 
A natureza interativa dos serviços também ajuda a entender o paradoxo de Solow, que se refere à observação de uso intensivo de tecnologias da informação e da comunicação (TIC) acompanhado de queda de produtividade no setor serviços. A produção ou o resultado das atividades de serviço não podem ser medidos do mesmo modo que nas indústrias, sob o risco de subestimação e distorção da realidade. O uso intensivo de TIC aumenta nos serviços, mas, no lugar de haver uma simples queda na produtividade, o que ocorre são fenômenos complexos que abrangem: 1) a alocação de pessoal para atividades que exigem maior interação com o cliente, como o private banking, 2) a resposta a exigências dos clientes como a ampliação da variedade de produtos oferecidos no comércio, a melhoria da qualidade ou a agregação de novos serviços à atividade principal. Esse movimento precisa ser estudado e entendido com novas ferramentas teóricas e analíticas, que permitam a avaliação mais pluralista e multicritério dos serviços (Gadrey, 2001).

Por fim, surge a abordagem integradora, que ambiciona juntar bens e serviços em uma teoria unificadora da inovação. Uma das justificativas para o desenvolvimento de uma teoria de inovação para o setor de serviços é a existência de especificidades no produto deste setor que fazem com que a teoria da inovação construída para estudar esse fenômeno na indústria seja insuficiente para ajudar a compreender a inovação em serviços. Para isso, apresenta uma formulação do produto (bens e serviços) em termos de vetores de características (Gallouj e Weinstein, 1997; Gallouj, 2002), ilustrada na figura a seguir.

Figura

Representação geral do produto em termos de vetores de características

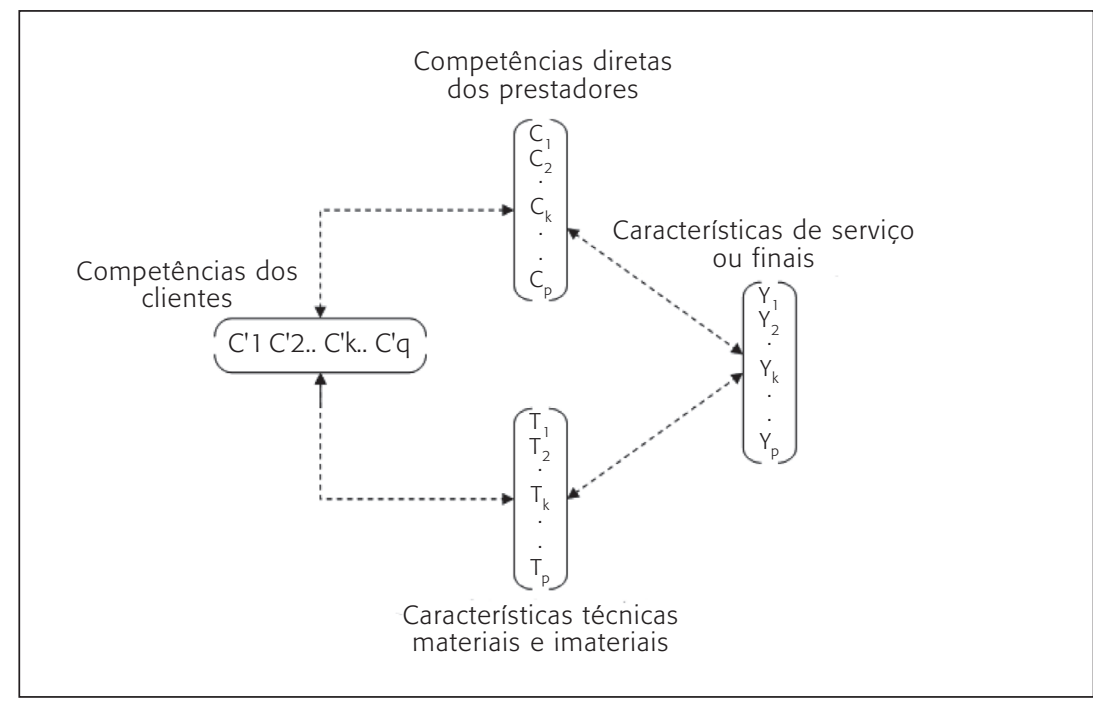

Fonte: adaptado de Gallouj (2002:58). 
Essa formulação permite abranger duas das especificidades do setor: a diversidade e o componente relacional dos serviços. O tratamento analítico dessa última ocorre pela incorporação de um vetor de competências dos clientes [C'] ao modelo. Como a formulação do autor é uma generalização de um modelo anterior usado para bens (Saviotti e Metcalfe, apud Gallouj, 2002:30), ela permite analisar de forma unificada tanto bens quanto serviços. Outro avanço teórico dessa abordagem é a incorporação à análise das antes negligenciadas características técnicas imateriais, que são sistemas de competências formalizadas e codificadas (Gallouj, 2002:56). O desenvolvimento do modelo de uma perspectiva evolucionária permite definir a inovação em termos de variações nos componentes dos vetores de características e formular uma tipologia de inovações que abrange bens e serviços.

Um tema ainda polêmico nos estudos de inovação em serviços e no setor público é o das formas de inovação, pois não há consenso sobre a tipologia, ao contrário do que ocorre nos estudos mainstream que usam a tipologia schumpeteriana (Schumpeter, 1982). É desejável obter-se alguma estabilidade na classificação das inovações para permitir sua análise quanto à natureza e viabilizar sua medição em estudos agregados e comparativos. Aqui discorreremos sobre modos de inovação propostos em estudos que usam a representação do produto como vetores de características.

Retomando a ideia de inovação como processo de variação em elementos estruturais da economia e a conjugando com a representação do produto dos serviços em termos de vetores de características, Gallouj (2002) identifica seis modos segundo os quais ocorre o processo de inovação.

O primeiro modo ou modelo é o de inovação radical, no qual ocorre a criação de um novo conjunto de vetores de características, configurando um novo produto. Segundo o autor, a definição mais ampla desse modelo abrange ainda o caso no qual surgem novas competências de clientes e produtores, bem como novas características técnicas materiais e imateriais, mas as características finais do produto não se alteram significativamente.

A inovação de melhoria envolve mudança na qualidade de certos componentes dos vetores de características do produto [Y], sem alterar a estrutura dos demais vetores. No caso particular de ocorrer apenas aperfeiçoamento de competências do produtor, que geram melhorias nas características finais do produto, não se diferenciaria do processo de aprendizagem organizacional. O autor argumenta que esse modo de inovação não pode ser ignorado em razão de seus efeitos cumulativos sobre a economia.

A inovação incremental descreve a ocorrência de aperfeiçoamento das características finais do produto por meio da adição ou substituição de componentes dos vetores por novas características. Para o autor, esse tipo de inovação é lugar comum, por exemplo, na indústria de seguros, na qual se acrescentam novas garantias e serviços à apólice básica, em caso de sinistro.

A inovação por recombinação é o modelo segundo o qual componentes dos vetores de características dos produtos dos serviços são combinados ou dissociados para formar novo produto. Um exemplo de combinação apresentado pelo autor é a criação dos resorts por meio da combinação de características de hotel e clube de luxo. Um exemplo de dissociação é a criação de hotéis básicos e baratos, como a concepção da linha Fórmula 1 da cadeia francesa 
Accord, por meio da eliminação de uma série de características de hotéis de alto padrão como o serviço de check-in e check-out, o frigobar, o restaurante.

A inovação por formalização é a sistematização documentada das características do produto, tornando-as mais visíveis e padronizadas. Essa forma de inovação ocorre em associação aos modelos ad hoc e por recombinação. Gallouj (2002) oferece o exemplo da auditoria legal, cujo produto sempre existiu e era prestado no contexto da consultoria jurídica. Por meio de processo de construção social, algumas das características do produto foram delimitadas, documentadas e deu-se o nome de auditoria legal a esse produto identificado. Após a formalização, tornou-se possível recombinar as características do serviço anterior e "extrair" dele a auditoria legal. A associação desse modelo de inovação à inovação ad hoc será tratada a seguir.

A inovação ad hoc é a construção conjunta de uma solução para o problema colocado pelo cliente por meio da interação entre este e o produtor/prestador de serviço que provoca alterações nas características do serviço. A natureza interativa desse tipo de inovação limita sua reprodutibilidade. No entanto, o produtor, por exemplo, uma consultoria, pode aprender novas competências e codificar (formalizar) o conhecimento para uso posterior em circunstâncias similares, o que demonstra a associação desse modelo à inovação por formalização.

Na seção seguinte são explicados o modo de seleção dos artigos revisados e quais foram as categorias de análise usadas em seu exame.

\section{Método}

Os artigos foram recuperados, na primeira semana de junho de 2010, de periódicos internacionais indexados na base science direct, no período de 2006 a 2010, com as palavras-chave innovation theory e public sector e que tivessem innovation e public no título. A pesquisa nos periódicos limitou-se a artigos que efetivamente tratassem de inovação no setor público para que fosse possível estabelecer o diálogo com os autores de inovação em serviços. Como resultado, foram recuperados sete artigos, todos de revistas Qualis A1, ou que assim se classificariam em razão de seu índice de impacto em pelo menos uma área de avaliação.

Esses estudos foram confrontados com a literatura internacional de inovação em serviços e analisados segundo seis categorias que serviram para revelar as abordagens adotadas pelos autores. A primeira categoria é a perspectiva da fundamentação teórica sobre inovação. Para Fuglsang (2010), a literatura sobre inovação e desenvolvimento no setor público pode ser classificada em cinco perspectivas. A primeira é a da administração pública, que foca reformas impostas de políticas públicas e, em particular, o papel da Nova Gestão pública (NGP). A segunda é a do neoinstucionalismo, que procura entender as mudanças em termos de processos de institucionalização, com ênfase em negociação no campo organizacional e na adaptação e legitimação das organizações. A terceira é a do Estado competidor, que foca na transformação do estado de bem-estar, em razão da globalização e da competição crescente entre países. A quarta corresponde ao empreendedorismo social e público, com foco no nível micro, nas motivações pessoais dos empreendedores. A quinta e última perspectiva referese à teoria da inovação, que aborda a inovação como atividade sujeita à incerteza e que se 
baseia em recursos heterogêneos e processos interativos. Esta análise opõe as três primeiras perspectivas, que enfatizam a pressão por mudanças com origem nas reformas em políticas públicas, com as duas últimas, que visam uma compreensão mais intrínseca da inovação como um processo interativo, que inclui a política pública.

A segunda categoria refere-se ao tipo da inovação considerado no artigo. Nesse caso, são usadas duas classificações: a de Schumpeter (1982) e a de Gallouj (2002). A tipologia clássica de Schumpeter (1982) menciona cinco tipos de inovação: 1) novo bem ou nova qualidade de bem (de produto), 2) novo processo de produção ou comercialização (de processo), 3) novo mercado (de mercado), 4) nova fonte de insumos (de insumos), 5) nova organização na indústria (organizacional). Como visto na seção anterior, Gallouj (2002) identifica seis modos segundo os quais ocorre o processo de inovação: 1) inovação radical, 2) inovação de melhoria, 3) inovação incremental, 4) inovação por recombinação, 5) inovação por formalização, 6) inovação ad hoc. Essa análise visa desvelar o tipo de inovação que tem chamado a atenção dos pesquisadores no setor público.

A terceira categoria define os artigos em três grupos, conforme a concepção do papel do setor público no processo de inovação. O primeiro grupo é formado por artigos que tratam o setor público como protagonista, isto é, como implementador de inovações dentro do serviço público. O segundo grupo trata o setor público como apoiador do setor comercial da economia, que é o implementador das inovações que terão efeito de desenvolvimento econômico. Nesse caso, o governo financia, fomenta ou fornece meios, como infraestrutura, para os processos de inovação protagonizados pelas firmas. O terceiro grupo reúne artigos que retratam o governo como consumidor de produtos inovadores gerados pelo setor privado (Koch e Hauknes, 2005; Windrum e García-Goñi, 2008).

As três categorias de análise seguintes têm caráter metodológico e são aplicadas com o objetivo de identificar as abordagens de pesquisas adotadas nos estudos revisados. O nível de análise identifica estudos em três graus de agregação: quando o foco são os indivíduos, a exemplo de empreendedores, o estudo é de nível micro; ao analisar organizações ou suas subunidades, os estudos são de nível meso; aqueles que examinam a inovação em conjunto de organizações de uma base geográfica, ou de ramo de serviço ou outra forma de agrupamento são considerados de nível macro.

O gênero da pesquisa será analisado conforme a classificação proposta por Demo (2000), isto é, pesquisa teórica, empírica, metodológica ou prática. A pesquisa teórica é dedicada a construir teoria, conceitos, ideias, quadros de referência, condições explicativas da realidade. A pesquisa empírica é dedicada ao tratamento da face fatual da realidade, mediante produção e análise de dados. A pesquisa metodológica volta-se para a inquirição de métodos e procedimentos científicos, mediante, por exemplo, o estudo dos paradigmas, das crises da ciência, dos métodos e das técnicas dominantes na produção científica. A pesquisa prática refere-se à prática histórica em termos de conhecimento científico para fins explícitos de intervenção.

Por fim, quanto ao método aplicado, os artigos são classificados entre qualitativos e quantitativos. Os qualitativos são aqueles que se propõem a incorporar a questão do significado e da intencionalidade como inerentes aos atos, às relações e às estruturas sociais, sendo es- 
sas últimas tomadas, tanto em seu advento quanto em sua transformação, como construções humanas significativas (Minayo apud Turato, 2005). Os quantitativos são aqueles que investigam sistematicamente propriedades dos fenômenos e suas relações por meio de processos de mensuração, procurando conexão entre a observação empírica e a modelagem matemática de suas propriedades mensuráveis.

\section{Síntese dos artigos revisados}

Esta seção é descritiva e faz a síntese dos estudos revisados, destacando seus objetivos, objetos e conclusões. A categoria gênero da pesquisa será usada para agrupar os artigos.

Três dos sete artigos revisados são empíricos, um é teórico e três são teórico-empíricos. Eles serão sintetizados a seguir, começando pelos empíricos.

Dorner (2009) objetiva estudar a difusão de práticas de preservação de registros digitais em organizações públicas da Nova Zelândia. O trabalho foi motivado pela aprovação de lei que obriga as organizações públicas a manter práticas de gestão de registros digitais para garantir sua preservação e o acesso do público. Com base na realização de survey, o autor conclui que são insuficientes o conhecimento e a consciência organizacional sobre as ameaças ao gerenciamento e à preservação das informações em razão de deficiências nas práticas de preservação dos registros digitais. Com fundamento na teoria da difusão das inovações de Rogers (Dorner, 2009), recomenda a designação de responsáveis, com perfil de paladinos (champions), pela implementação da nova lei em cada uma das organizações públicas.

Potnis (2010) avalia o método de mensuração da inovação em governo eletrônico em surveys realizadas pelas Nações Unidas (ONU). O autor argumenta que a relevância do estudo está em avaliar a qualidade dessas pesquisas para informar seus usuários, entre os quais estão acadêmicos e profissionais dos governos. Usando pesquisa documental e análise de conteúdo conceitual, bem como o quadro conceitual de medição da gestão da inovação, ${ }^{2}$ o autor formula recomendações para aperfeiçoar as surveys da ONU.

Raus, Flügge e Boutellier (2009) procuram identificar facilitadores e barreiras para a difusão entre países europeus de sistemas informatizados padronizados de desembaraço aduaneiro. Justificam a pesquisa pela importância de melhorar a eficiência dos serviços governamentais ligados ao comércio entre países e o estudo da difusão das diretrizes da UE para sistemas informatizados de controle aduaneiro. Os autores fazem estudo de caso em projeto europeu de desenvolvimento desse sistema. Aplicam entrevistas, realizam workshop e pesquisa documental. Usando a teoria da difusão da inovação de Rogers (Raus, Flügge e Boutellier, 2009), os autores analisam o estudo de caso e identificam três barreiras e quatro facilitadores do processo de inovação. ${ }^{3}$

\footnotetext{
2 The Innovation Management Measurement Framework (IMMF).

${ }^{3}$ Facilitadores: benefício potencial, melhoria de procedimentos e modernização de processos comerciais, impedimento de má interpretação de regulamentos, padronização de processos e de formatação de dados e informações. Barreiras: redução da velocidade da regulação, aumento na complexidade da padronização, mecanização das operações.
} 
Em artigo teórico, Dai e colaboradores (2009) analisam os possíveis mecanismos de interação entre o governo e os principais atores envolvidos na implementação de eventual nova política pública de eficiência energética de edifícios. Os autores argumentam que falta à China uma política de supervisão da eficiência energética de grandes edifícios públicos e comerciais, o que justifica a pesquisa. Por meio de revisão bibliográfica e usando a teoria da regulação, propõem o conceito de mudança e redesenho da supervisão governamental sobre a eficiência energética de edifícios.

As pesquisas teórico-empíricas foram assim classificadas porque realizaram investigação empírica visando construir modelos e quadros de referência com ambição explicativa. Choi e Chang (2009) têm por objetivo estudar os efeitos de fatores institucionais e de processos coletivos, baseados nos empregados, ${ }^{4}$ sobre a efetividade da inovação e de sua implementação. Os autores justificam o estudo pela lacuna existente na literatura de um quadro de referência que permita integrar a análise dos fatores institucionais e processos coletivos sobre o processo de inovação. A pesquisa abrange survey com organizações públicas coreanas sobre implementação de governo eletrônico, painéis com especialistas e surveys com empregados, sendo esses dois últimos realizados em três momentos. As surveys são analisadas por meio de equações estruturais, e hipóteses sobre associação entre as variáveis foram testadas. O marco teórico inclui a teoria institucional, a literatura de implementação e a teoria da difusão de inovações de Rogers (Choi e Chang, 2009). Os autores concluem que os processos coletivos medeiam os efeitos institucionais sobre a implementação das inovações e seus resultados.

Edler e Georghiou (2007) visam analisar o conceito de compra governamental como ferramenta da política de inovação nos países. O interesse dos autores foi despertado pela emergência das discussões sobre a ligação entre compras do governo e investimento em P\&D pelas firmas na agenda política da União Europeia (UE). Por meio de revisão bibliográfica e documental, os autores criam quadro de referência, que inclui taxonomia de políticas de inovação, para analisar as compras governamentais como ferramentas de política de inovação e recomendar sua consideração no desenho das políticas de inovação.

Naranjo-Gil (2009) estuda as relações entre fatores ambientais e organizacionais ${ }^{5}$ na adoção de inovações e a relação entre a adoção de inovações e o desempenho das organizações. O autor justifica a pesquisa pela necessidade de entender melhor as relações entre essas variáveis, considerando ainda a lacuna de trabalhos que examinam diferentes tipos de inovações ${ }^{6}$ simultaneamente. A pesquisa abrange survey com organizações públicas da área da

\footnotetext{
${ }^{4}$ Fatores institucionais: apoio gerencial, disponibilidade de recursos, apoio à aprendizagem. Processos coletivos: percepção coletiva dos empregados sobre sua capacidade para implementar a inovação, aceitação da inovação pelos empregados com base na percepção de benefícios potenciais pessoais e para a organização.

${ }^{5}$ Fatores organizacionais: estratégia e porte da organização. Fatores ambientais: grau de incerteza e concentração.

${ }^{6}$ Inovações técnicas: oferecimento de novos exames de imagem, como tomografia computadorizada axial, gama câmara e bomba de cobalto. Inovações administrativas: novas técnicas de gestão da informação e de controle, como o uso do balanced score card, do benchmarking e da curva ABC.
} 
saúde na Espanha, bem como pesquisa documental. O marco teórico abrange a NGP e a teoria da contingência. Os dados foram analisados por meio de regressão de mínimos quadrados parciais, e hipóteses sobre associação entre as variáveis foram testadas. O autor conclui que as organizações que adotam inovações técnicas e administrativas são mais sensíveis a fatores ambientais que organizacionais. Além disso, organizações que adotam os dois tipos de inovações aumentam seu desempenho. ${ }^{7}$

Na seção seguinte apresentamos os resultados da análise dos artigos, conforme as categorias definidas na seção de método, e discutimos esses resultados.

\section{Análise e discussão dos resultados}

A tabela a seguir apresenta a síntese dos resultados da revisão dos artigos, segundo as seis categorias de análise, além de uma coluna adicional que informa o objeto da inovação examinado pelas pesquisas.

Resumem-se a apenas duas as perspectivas teóricas dos artigos: quatro adotam a administração pública e três o Estado competidor. Os primeiros foram assim classificados porque enfocam reformas impostas de políticas públicas e em sua interação com a administração pública (Dai et al., 2009; Dorner, 2009) ou citam expressamente a NGP em sua contextualização ou fundamentação teórica (Choi e Chang, 2009; Naranjo-Gil, 2009). Os que adotam a perspectiva do Estado competidor abordam a inovação como estratégia para os países ganharem vantagem no mercado globalizado e fazem comparações entre as práticas adotadas pelos países (Edler e Georghiou, 2007; Potnis, 2010; Raus, Flügge e Boutellier, 2009). Todos os artigos, portanto, filiam-se a perspectivas que enfatizam a pressão por mudanças com origem em reformas "de cima para baixo" de políticas públicas. Não significa, no entanto, que na literatura inexistam pesquisas que adotem perspectivas que, segundo Fuglsang (2010), abordam a inovação como processo interativo coletivo e intrínseco à administração pública. Certamente as restrições impostas à seleção dos artigos, como descrito na seção de método, influenciaram neste resultado. Não obstante, como sugerido por Fuglsang (2010), as perspectivas identificadas de fato pertencem ao grupo predominante na literatura de inovação.

Outras três categorias revelaram temas predominantes entre os artigos revisados. $\mathrm{O}$ Estado como protagonista do processo de inovação é a percepção dominante do papel do setor público em cinco dos sete artigos. Isso não significa que esta seja a percepção que predomina na literatura de inovação. Novamente, a forma de seleção dos artigos influenciou o resultado, pois os artigos tratam de pesquisas interessadas em inovação no setor público. Por sua vez, cinco dos sete artigos tratam de inovações de processo, na terminologia de Schumpeter (1982), ou de melhoria, na terminologia de Gallouj (2002). Analisam ${ }^{8}$ novas

\footnotetext{
${ }^{7}$ Indicadores de desempenho: taxa de ocupação de leitos, taxa de uso de salas de cirurgia, taxa de readmissão de pacientes, tempo de permanência, taxa de mortalidade, tempo de espera.

${ }^{8}$ Potnis (2010) não analisa diretamente um processo de inovação, mas pesquisas sobre inovação na área de governo eletrônico.
} 
formas de prestação de serviços já existentes, aperfeiçoados pela introdução de sistemas eletrônicos ou equipamentos ou novas práticas gerenciais. Esse padrão não é surpreendente, considerando que os serviços têm natureza processual (Gallouj, 2002). Chama atenção também que quatro dos sete artigos examinam processos de inovação nos quais as tecnologias da informação e da comunicação são determinantes. Esse fato pode sugerir que no setor de serviços públicos as oportunidades tecnológicas e o paradigma tecnológico (Dosi, 2005) estão associados às TIC.

\section{Tabela}

\section{Síntese dos artigos internacionais revisados, segundo categorias de análise}

\begin{tabular}{|c|c|c|c|c|c|c|c|}
\hline Artigo & $\begin{array}{l}\text { Perspectiva } \\
\text { teórica }\end{array}$ & $\begin{array}{l}\text { Tipo de } \\
\text { inovação }\end{array}$ & $\begin{array}{l}\text { Concepção } \\
\text { do papel do } \\
\text { setor público }\end{array}$ & $\begin{array}{l}\text { Nível } \\
\text { de } \\
\text { análise }\end{array}$ & Gênero & Método & $\begin{array}{l}\text { Objeto da } \\
\text { inovação }\end{array}$ \\
\hline $\begin{array}{l}\text { Choi e } \\
\text { Chang } \\
(2009)\end{array}$ & $\begin{array}{l}\text { administração } \\
\text { pública }\end{array}$ & $\begin{array}{l}\text { De processo }(S) ; \\
\text { de melhoria }(G)\end{array}$ & protagonista & meso & $\begin{array}{l}\text { teórica- } \\
\text { empírica }\end{array}$ & $\begin{array}{l}\text { Quantitativo. Survey } \\
\text { longitudinal, dados } \\
\text { modelados por } \\
\text { equações estruturais } \\
\text { e posteriores testes } \\
\text { de hipóteses sobre } \\
\text { as relações entre as } \\
\text { variáveis }\end{array}$ & $\begin{array}{l}\text { governo } \\
\text { eletrônico }\end{array}$ \\
\hline $\begin{array}{l}\text { Dai et al. } \\
\text { (2009) }\end{array}$ & $\begin{array}{l}\text { administração } \\
\text { pública }\end{array}$ & $\begin{array}{l}\text { Radical (G), de } \\
\text { produto (S) }\end{array}$ & $\begin{array}{l}\text { protagonista; } \\
\text { apoiador }\end{array}$ & macro & teórica & $\begin{array}{l}\text { Qualitativo. Revisão } \\
\text { bibliográfica }\end{array}$ & $\begin{array}{l}\text { nova política } \\
\text { pública }\end{array}$ \\
\hline $\begin{array}{l}\text { Dorner } \\
\text { (2009) }\end{array}$ & $\begin{array}{l}\text { administração } \\
\text { pública }\end{array}$ & $\begin{array}{l}\text { De processo }(S) ; \\
\text { de melhoria }(G)\end{array}$ & protagonista & meso & empírica & Quantitativo. Survey & $\begin{array}{l}\text { práticas de } \\
\text { preservação de } \\
\text { registros digitais }\end{array}$ \\
\hline $\begin{array}{l}\text { Edler e } \\
\text { Georghiou } \\
\text { (2007) }\end{array}$ & $\begin{array}{l}\text { Estado } \\
\text { competidor }\end{array}$ & diversificado & apoiador & macro & $\begin{array}{l}\text { teórica- } \\
\text { empírica }\end{array}$ & $\begin{array}{l}\text { Qualitativo. Análise } \\
\text { documental }\end{array}$ & diversificado \\
\hline $\begin{array}{l}\text { Naranjo-Gil } \\
(2009)\end{array}$ & $\begin{array}{l}\text { administração } \\
\text { pública }\end{array}$ & $\begin{array}{l}\text { Organizacional e } \\
\text { processual (S). } \\
\text { Incremental e de } \\
\text { melhoria (G) }\end{array}$ & consumidor & meso & $\begin{array}{l}\text { teórica- } \\
\text { empírica }\end{array}$ & $\begin{array}{l}\text { Quantitativo. Survey, } \\
\text { pesquisa documental }\end{array}$ & $\begin{array}{l}\text { novos exames } \\
\text { de imagem } \\
\text { e técnicas } \\
\text { gerenciais e de } \\
\text { análise de dados }\end{array}$ \\
\hline $\begin{array}{l}\text { Potnis } \\
(2010)\end{array}$ & $\begin{array}{l}\text { Estado } \\
\text { competidor }\end{array}$ & $\begin{array}{l}\text { De processo }(S) \text {; } \\
\text { de melhoria }(G)\end{array}$ & protagonista & macro & empírica & $\begin{array}{l}\text { Qualitativo. Análise } \\
\text { documental e } \\
\text { análise de conteúdo } \\
\text { conceitual }\end{array}$ & $\begin{array}{l}\text { governo } \\
\text { eletrônico }\end{array}$ \\
\hline $\begin{array}{l}\text { Raus, } \\
\text { Flügge e } \\
\text { Boutellier } \\
\text { (2009) }\end{array}$ & $\begin{array}{l}\text { Estado } \\
\text { competidor }\end{array}$ & $\begin{array}{l}\text { De processo }(S) \text {; } \\
\text { de melhoria }(G)\end{array}$ & protagonista & macro & empírica & $\begin{array}{l}\text { Qualitativo. Estudo } \\
\text { de caso }\end{array}$ & $\begin{array}{l}\text { governo } \\
\text { eletrônico }\end{array}$ \\
\hline
\end{tabular}

S - classificação de Schumpeter (1982), G - classificação de Gallouj (2002).

Fonte: elaboração própria com base nos artigos revisados. 
Estudos de inovação em serviços que têm por objeto TIC são comuns, mas o tratamento que é dado ao tema difere do observado nos artigos revisados. Nesta amostra, a adoção de soluções informatizadas para aperfeiçoar os serviços poderia se beneficiar de análise mais detalhada que revelasse mudanças nas competências dos atores envolvidos e na organização dos serviços. Poderiam ser exploradas questões como: a adoção da nova tecnologia permitiu a criação de novos serviços ou a agregação de novas características aos serviços existentes? Quais foram as novas competências que tiveram que ser desenvolvidas por prestadores de serviço e usuários? Quais foram as mudanças nas relações entre prestadores e usuários? Quais foram as competências técnicas materiais e imateriais que precisaram ser desenvolvidas em razão da adoção da nova tecnologia? Para empreender esse tipo de investigação, a representação do produto em termos de vetores de características pode revelar processos antes despercebidos, que viabilizem a avaliação mais pluralista e multicritério dos serviços (Gadrey, 2001).

Todos os três artigos que adotaram a perspectiva do Estado competidor aplicaram método qualitativo de investigação. Todos usaram pesquisa documental; Potnis (2010) e Edler e Georghiou (2007) a usaram exclusivamente, enquanto Raus, Flügge e Boutellier (2009) a associaram ao estudo de caso. Apenas Potnis (2010) afirma ter analisado seus dados por meio de análise de conteúdo. Três dos quatro artigos que adotaram a perspectiva da administração pública aplicaram método quantitativo em análise de surveys. Enquanto Choi e Chang (2009) e Naranjo-Gil (2009) modelaram os dados usando equações estruturais e regressão dos mínimos quadrados parciais, Dorner (2009) limitou-se a analisar as frequências das respostas à survey. Do grupo da administração pública, apenas Dai e colaboradores (2009) aplicaram método qualitativo, restrito à revisão bibliográfica. Um padrão entre perspectiva teórica e método não fica claro com esses dados, mas a relação fica mais evidente ao adicionarmos o nível de análise e o objeto da inovação.

Nenhum artigo realizou análise no nível micro. Todos os quatro artigos cujo nível de análise era macro aplicaram método qualitativo de investigação. Três deles examinavam políticas públicas: de compras governamentais (Edler e Georghiou, 2007), de informatização de serviços aduaneiros (Raus, Flügge e Boutellier, 2009) e de eficiência energética de edifícios (Dai et al., 2009). Os estudos classificados como meso, apesar de analisarem grupos de organizações, estudavam a relação entre variáveis no nível organizacional. Um único artigo examinou política pública, mas aplicou método quantitativo e analisou seu problema no nível meso (Dorner, 2009). Por sua vez, todos os artigos cujo nível de análise era meso adotaram método quantitativo, usando survey.

No estudo da inovação no setor público a tensão micro-macro acentua-se porque os processos de inovação estão ajustados em grandes e complexas estruturas organizacionais e desenvolvidos de forma aceitável política e legalmente, consideradas ainda preocupações sobre equidade social e eficiência. A maior parte das organizações públicas é elemento de uma grande cadeia de comando e controle no qual é difícil traçar uma linha entre as diferentes partes do sistema (Koch e Hauknes, 2005:19, 24). A perspectiva macro pode perder em sua análise as características locais, as interações entre os atores, as soluções idiossincráticas (Donahue, apud Farah, 2007) ou ad hoc (Gallouj, 2002) e a influência do contexto. A perspectiva 
estritamente organizacional pode perder as contingências do ambiente político-social que atuam sobre a trajetória de inovação.

Alguns estudos de inovação em serviços e na manufatura enfrentam o mesmo problema. Em serviços, há autores que usam a Actor-Network Theory (ANT) para combinar as perspectivas institucional e organizacional (Vargas, 2009). Segundo Latour (2005), a noção de rede permite dissolver a distinção micro-macro que tem assolado a teoria social desde seu início. Malerba (2004) também identifica essa tensão nas pesquisas de inovação e propõe aplicar o quadro referência dos sistemas setoriais de inovação para superá-la.

Assim, considerando os resultados apresentados, a amostra examinada revela as seguintes relações:

Relação $1 \rightarrow$ Estado competidor -> nível macro -> método qualitativo -> análise de política pública

Relação $2 \rightarrow$ administração pública $->$ nível meso $\rightarrow>$ método quantitativo $->$ aplicação de survey $\rightarrow>$ investigação de relação entre variáveis no nível organizacional

Essas relações indicam duas vertentes nos estudos de inovação em serviços públicos: uma que pode ser chamada de vertente do Estado competidor e a outra de vertente da Administração pública. Ao mesmo tempo, indicam caminhos poucos explorados pelas pesquisas. Por exemplo, destaca-se a ausência de estudos que examinem o empreendedorismo público ou social, de uma perspectiva micro (Fuglsang, 2010). Também estão ausentes estudos que tenham como base a teoria da inovação em serviços.

A perspectiva da inovação em serviços ressalta propulsores internos e externos da inovação em ambientes com interações complexas (Fuglsang, 2010). Essas investigações poderiam contribuir com pesquisas que examinam as relações entre variáveis que influenciam a inovação, sugerindo novas variáveis e relações a serem testadas. Dessa forma, poderiam ser incorporadas à análise relações com atores políticos, fornecedores e a comunidade usuária dos serviços. Esse é o caso em especial dos autores que se engajaram em estudos quantitativos com modelagem estatística (Choi e Chang, 2009; Naranjo-Gil, 2009). Os artigos que analisaram melhor as relações complexas entre atores que atuam no processo de inovação foram os de Dai e colaboradores (2009) e de Edler e Georghiou (2007). O primeiro é teórico e o segundo teórico-empírico. Essa ambição de desenvolver quadros de referência e conceitos analíticos pode ter impulsionado esses autores a adotar visão mais abrangente do processo de inovação.

Outra contribuição dos estudos de inovação em serviços é o reconhecimento do caráter processual da inovação. Raus, Flügge e Boutellier (2009) e Dorner (2009) abordam políticas públicas e partem delas como artefatos, pontos de início e fatores exógenos, quando de fato elas são continuamente constituídas e negociadas na prática de sua implementação, oportunidade na qual os problemas são revelados e surgem soluções que respondem a eles.

As referências de boa parte dos artigos indicam que a revisão bibliográfica sobre inovação tem sido restrita, em alguns casos ignorando os clássicos da teoria evolucionária e da inovação. Dai e colaboradores (2009) apresentam apenas oito referências no total. Seis publi- 
cadas em chinês, exceto uma sobre microeconomia e outra sobre economia do setor público, ambas, porém, publicadas na China, o que sugere que os autores não procuraram ou não têm acesso ao estado da arte em seu campo de pesquisa. Nenhuma menção é feita a autores sobre inovação. Dorner (2009) apresenta apenas 18 referências no total, sendo nove documentos governamentais e uma autocitação. A teoria da difusão da inovação de Rogers (apud Dorner, 2009) é a única referência à literatura de inovação. Aliás, é curioso que entre referências tão restritas, Rogers seja citado em três dos sete artigos. Raus, Flügge e Boutellier (2009) argumentam que o autor é muito aceito e mencionam um estudo de Prescott e Conger (de 1995) no qual eles registram 70 artigos publicados entre 1984 e 1994 que usaram a teoria de Rogers. Potnis (2010), Choi e Chang (2009) e Naranjo-Gil (2009) citam artigos que tratam de inovação, mas não mencionam nenhum autor da literatura básica de inovação. Apenas dois artigos citam autores já consagrados na literatura de inovação: Raus, Flügge e Boutellier (2009) citam L. Soete e J.M. Utterback; Edler e Georghiou (2007) citam Richard Nelson, B. Lundvall e C. Edquist.

Essa pesquisa restrita sobre as bases teóricas da teoria da inovação e seu desenvolvimento posterior pode estar na origem da limitação de perspectivas teóricas presentes nos artigos revisados.

\section{Conclusões}

Uma vez revisados artigos sobre inovação no setor público, publicados em periódicos internacionais Qualis A1 no período de 2006 a 2010, realizou-se confronto das formulações adotadas na amostra com a literatura sobre inovações em serviços que adota a abordagem integradora.

Ressalvando que o conjunto de artigos revisados é pequeno e a base de informação restrita para permitir afirmações fortes, a revisão possibilitou caracterizar a produção internacional ao inventariar seus objetivos, métodos, enfoques teóricos e resultados. Permitiu também identificar temas e formulações da literatura de inovação em serviços que podem contribuir para tornar a análise sobre inovação no setor público mais rica e mais completa, reconhecendo as especificidades dos serviços.

A análise dos artigos revela que não há relação clara entre o gênero da pesquisa e as demais categorias de análise. Predominam artigos que tratam de inovação processual ou de melhoria, nos quais as TIC têm papel de relevo.

Evidenciou-se também que há oportunidades de pesquisa na investigação de processos de inovação organizacional (Schumpeter, 1982), incremental, por recombinação, por formalização e ad hoc (Gallouj, 2002).

A amostra de artigos revisados é relativamente pequena e indicou apresentar interação restrita com a literatura sobre inovação em serviços. De um lado, há artigos que adotam perspectiva teórica da administração pública e, de outro, os que adotam a perspectiva 
do Estado competidor. Para entender a inovação nos serviços públicos, é necessário explorar novas perspectivas e examinar o fenômeno de outros ângulos, agregando as contribuições dos estudos que abordam o nível micro de análise e que assumem a perspectiva da teoria da inovação em serviços, de forma a abarcar a complexidade e a diversidade do setor público.

$\mathrm{Na}$ linha dos artigos que tratam de estudos de caso, a representação do produto em termos de vetores de características sugere tipologia de inovação que pode tornar a identificação e medição das inovações no serviço público mais coerentes com as especificidades dos serviços. Abordagens adotadas na literatura de inovação em serviços oferecem base teórica para os estudos que pretendem examinar os efeitos da inovação nos serviços públicos, conciliando a avaliação da eficiência com a avaliação de dimensões cívicas e sociais, que são intrínsecas à atividade dos serviços públicos. Por fim, a ANT permite trabalhar melhor a tensão e as limitações de análises macro e micro, oferecendo oportunidades de abranger, com maior detalhe, o nível organizacional na investigação dos processos de inovação no serviço público.

\section{Referências}

CHOI, J.N.; CHANG, J.Y. Innovation implementation in the public sector: an integration of institutional and collective dynamics. Journal of Applied Psychology, v. 94, n. 1, p. 245-253, 2009.

DAI, X.; WU, Y.; DI, Y.; LI, Q. Government regulation and asssociated innovations in building energy-efficiency supervisory systems for large-scale public buildings. Energy Policy, n. 37, p. 20732078, 2009.

DEMO, Pedro. Metodologia do conhecimento científico. São Paulo: Atlas, 2000.

DORNER, D.G. Public sector readines for digital preservation in New Zeland: the rate of adoption of an innovation in records management practices. Government Information Quaterly, n. 26, p. 341-348, 2009.

DOSI, G. Mudança técnica e transformação industrial: a teoria e uma aplicação à indústria dos semicondutores. Campinas: Ed. Unicamp, 2005.

EDLER, J.; GEORGHIOU, L. Public procurement and innovation. Resurrecting the demand side. Research policy, n. 36, p. 949-963, 2007.

FARAH, M. Continuidade e disseminação de inovações na gestão pública subnacional no Brasil. In: CONGRESSO INTERNACIONAL DEL CLAD SOBRE LA REFORMA DEL ESTADO Y DE LA ADMINISTRACIÓN PÚBLICA, XII, Caracas, 2007. Anais... Disponível em: <www.clad.org.ve/fulltext/0057930.pdf>. Acesso em: 3 nov. 2009.

FUGLSANG, L. Bricolage and invisible innovation in public service innovation. Journal of Innovation Economics, n. 5, p. 67-87, 2010. 
GADREY, Jean. Emprego, produtividade e avaliação do desempenho dos serviços. In: SALERNO, M.S. (Org.). Relação de serviço: produção e avaliação. São Paulo: Senac São Paulo, 2001.

GALLOUJ, Faïz. Innovation in the service economy: the new wealth of nations. Cheltenham, UK: Edward Elgar Publishing Limited, 2002.

GALLOUJ, F.; SAVONA, M. Innovation in services: a review of the debate and a research agenda. Journal of Evolutionary Economics, v. 19, n. 2, p. 149-172, 2009.

GALLOUJ, Faïz; WEINSTEIN, Olivier. Innovation in services. Research Policy, n. 26, p. 537-556, 1997.

INSTITUTO BRASILEIRO DE GEOGRAFIA E ESTATÍSTICA (IBGE). Estatísticas do século XX. Rio de Janeiro: IBGE, 2006. Disponível em: <www.ibge.gov.br/seculoxx/economia/contas_nacionais/ contas_nacionais.shtm>. Acesso em: 28 mar. 2010.

INSTITUTO DE PESQUISAS APLICADAS (IPEA). Presença do Estado no Brasil: federação, suas unidades e municipalidades. Brasília: Ipea, 2009.

KOCH, P.; HAUKNES, J. Innovation in the Public Sector. Publin Report n. D20. Oslo: NIFU STEP, 2005. Disponível em: <http://www.step.no/publin/>. Acesso em: 3 nov. 2009.

LATOUR, B. Reassembling the social: an introduction to Actor-Network Theory. Oxford: Oxford University Press, 2005.

MALERBA, F. Sectoral systems of innovation: basic concepts. In: (Ed.). Sectoral systems of innovation: concepts, issues and analyses of six major sectors in Europe. Cambridge: Cambridge University Press, 2004.

NARANJO-GIL, D. The influence of environmental and organizational factors on innovation adoptions: consequences for performance in public sector organizations. Technovation, n. 29, p. 810-818, 2009.

NELSON, R.; WINTER, S. Uma teoria evolucionária da mudança econômica. Campinas: Unicamp, 2005.

POTNIS, D.D. Measuring e-Governance as an innovation in the public sector. Government Information Quaterly, n. 27, p. 41-48, 2010.

RAUS, M.; FLÜGGE, B.; BOUTELLIER, R. Electronic customs innovation: an improvement of governmental infrastructures. Government Information Quaterly, n. 26, p. 246-256, 2009.

SCHUMPETER, Joseph. A teoria do desenvolvimento econômico. São Paulo: Abril Cultural, 1982. (Os economistas)

TURATO, E.R. Métodos qualitativos e quantitativos na área da saúde: definições, diferenças e seus objetos de pesquisa. Revista de Saúde Pública, v. 39, n. 3, p. 507-514, 2005.

VARGAS, E.R. A dinâmica da inovação em serviços: o caso dos serviços hospitalares no Brasil e na França. Tese (doutorado) — Universidade Federal do Rio Grande do Sul, Porto Alegre, 2006. 
VARGAS, E.R. La dynamique de l'innovation dans les services: les cas des services hospitaliers, une comparison Brésil-France. Économies et Sociétés, v. 10, n. 4, p. 615-640, 2009.

WINDRUM, P.; GARCÍA-GOÑI, M. A neo-schumpeterian model of health services innovation. Research Policy, n. 37, p. 649-672, 2008.

Dagomar Henriques Lima é auditor federal de controle externo no Tribunal de Contas da União. E-mail: direito-bsb@ig.com.br.

Eduardo Raupp de Vargas é professor do Programa de Pós-Graduação em Administração da Universidade de Brasília (PPGA/UnB). E-mail: raupp.vargas@gmail.com. 
